Editorial

\title{
Severe Plastic Deformation and Thermomechanical Processing: Nanostructuring and Properties
}

\author{
Andrea Bachmaier ${ }^{1} \mathbb{D}$, Thierry Grosdidier ${ }^{2}$ and Yulia Ivanisenko ${ }^{3, *}$ \\ 1 Erich Schmid Institute of Materials Science of the Austrian Academy of Sciences, Jahnstrasse 12, \\ 8700 Leoben, Austria; andrea.bachmaier@oeaw.ac.at \\ 2 Laboratoired'Etude des Microstructures et de Mécanique des Matériaux (LEM3), Université de Lorraine, \\ CNRS UMR 7239, 7 rue Félix Savart, 57073 Metz, France; thierry.grosdidier@univ-lorraine.fr \\ 3 Karlsruhe Institute of Technology, Campus North, Institute of Nanotechnology, \\ 76344 Eggenstein-Leopoldshafen, Germany \\ * Correspondence: julia.ivanisenko@kit.edu; Tel.: +49-721-60826961
}

Received: 21 September 2020; Accepted: 28 September 2020; Published: 29 September 2020

check for updates

\section{Introduction and Scope}

The research field of severe plastic deformation (SPD) offers innovative potential for manufacturing bulk metallic materials as well as for modifying their surfaces. Significant grain refinement can be obtained using hot, warm, cold, and even cryogenic deformations by SPD and Thermo-Mechanical Processing (TMP), or a combination thereof. In addition to grain refinement in the respective phases of the metallic materials, microstructural design on different hierarchical levels and even alloy design by phase formations and transformations during processing is possible by SPD and TMP. Examples include mechanically driven phase transformations, the formation of metastable phases, grain boundary engineering, and the formation of desirable textures.

This Special Issue contains the selected papers presented at the 3rd Symposium, "Severe Plastic Deformation and Thermomechanical Processing: Nanostructuring and Properties", which was organised as a part of EUROMAT congress in Stockholm, Sweden, 1-5 September, 2019.

The published papers report the use and recent advancements of different established as well as novel SPD processes like high-pressure torsion (HPT), Equal-Channel Angular Pressing (ECAP), High-Pressure Torsion Extrusion (HPTE) and Surface Mechanical Attrition Treatment (SMAT). In the scope of these studies are microstructural evolution, phase formations and grain refinement in singleand multi-phase alloys, strategies to enhance the microstructural stability at elevated temperatures as well as during thermal cycling and the improvement of mechanical and physical properties by SPD processing. Additionally, the biomedical properties of SPD-processed materials are investigated.

\section{Contributions}

Thirteen research papers have been published in this Special Issue of Metals. The papers cover a wide spectrum of topics, including (i) deformation mechanisms, the mechanical properties and fatigue behaviour of SPD-processed materials [1-7], (ii) microstructural and mechanical stability at elevated temperatures [8,9], phase formations in alloys [10], the improvement of physical properties (electrical conductivity [11], magneto-resistance [12]) and biomedical properties (biocorrosion resistance [6], biocompatibility [13]) by SPD.

In the thematic area (i), Klu et al. [1] investigated a combination of multi-pass warm ECAP followed by rolling at room temperature for the development of a high-strength Mg-9Li duplex alloy and carried out a systematic investigation of the microstructure-mechanical properties relationship. They found that grain boundary strengthening and dislocation strengthening are the main factors 
determining the strength of this alloy. Additionally, the basal texture of the $\alpha-\mathrm{Mg}$ phase, which was induced by the rolling process, contributed to the strength. Nugmanov et al. [2] examined the structure and tensile strength of pure $\mathrm{Cu}$ after HPTE. A gradient structure developed due to the strain varying across the sample from the central area to the edge. Nevertheless, similar strength values as in pure $\mathrm{Cu}$ with a homogeneous microstructure after SPD were reached, which demonstrates the potential of HPTE for future industrial use. Stráská et al. [3] processed a low alloyed $\mathrm{Mg}-\mathrm{Zn}-\mathrm{Nd}$ alloy by hot extrusion and subsequent ECAP deformation. The influence of texture and microstructure on the mechanical properties and deformation mechanisms was thoroughly studied and a compressive yield strength more than twice as high as that of the undeformed alloy was reached. Dureau et al. [4] investigated the influence of ultrasonic SMAT treatment at room and cryogenic temperatures on the fatigue behaviour of a 304L austenitic stainless steel with a focus on the nature of the cyclic loading conditions. In the case of this steel, the higher fraction of martensite induced by the cryogenic SMAT did not provide an enhancement of fatigue performance compared with the room temperature treatment. However, the fatigue limit was increased by approximately $30 \%$ for both peening temperatures in comparison with the untreated samples. Industrial scale multi-pass rotary-die ECAP processing was used in [5] to tailor the morphology and distribution of $\mathrm{Al}_{2} \mathrm{Ca}$ particles in a Mg-Al-Ca-based alloy to improve its strength and ductility. The alloy with the finest and most homogenously dispersed $\mathrm{Al}_{2} \mathrm{Ca}$ particles exhibited superior mechanical properties, which were also attributed to refined grains of the $\alpha-\mathrm{Mg}$ phase and nanosized $\mathrm{Mg}_{17} \mathrm{Al}_{12}$ precipitates. The effects of thermomechanical processing (SPD by HPT and thermal treatment) on the mechanical properties of biodegradable $\mathrm{Mg}$ alloys were investigated by Ojdanic et al. in [6]. Thermomechanical processing lead to a strength increase of up to $250 \%$, whereby about $1 / 3$ of the increase could be related to the thermal treatment. Differential scanning calorimetry and X-ray line profile analysis proofed a significant contribution of the high vacancy concentration to the extensive hardening of the investigated alloys. Furthermore, intermetallic precipitates contributed to the strength. Veverková et al. [7] evaluated the mechanical properties of a metastable $\beta$-Ti alloy Ti-15Mo, which was prepared by cryogenic milling and spark plasma sintering. By using this process, a refined microstructure with very high strength levels could be obtained.

In the framework of topic (ii), the microstructural and mechanical stability during elevated temperatures is discussed in two papers. Kriegel et al. [8] investigated the formation and thermal stability of the $\omega$ - $\mathrm{Ti}(\mathrm{Fe})$ phase in $\alpha$-phase-based $\mathrm{Ti}(\mathrm{Fe})$ alloys, which were processed by HPT. The formation of the $\omega$-Ti $(\mathrm{Fe})$ phase was mainly at the expense of $\alpha$-Ti. The thermal stability of the studied alloys was lower than that of samples, annealed above the eutectoid reaction. However, a similar decomposition pathway was found. Churakova and Gunderov [9] analysed the influence of thermal cycling on the microstructural and mechanical stability of a Ti-Ni shape memory alloy, which was processed by ECAP, and compared it to a coarse-grained, undeformed counterpart. It was found that the ECAP-processed alloy is more attractive for applications, due to its higher level of properties compared to the coarse-grained state, and its higher stability during thermal cycling.

The effect of HPT and subsequent isothermal annealing on phase evolution and transformation in a Ti15Mo alloy was studied by Bartha et al. in [10]. They showed that, thanks to the increase in nucleation sites due to HPT-induced lattice defects, the $\alpha$-phase formation is enhanced. Furthermore, it was found that the $\alpha$-precipitates are small and equiaxed. Additionally, the microhardness is increased, which is mainly attributed to the microstructural refinement in combination with the formation of the $\omega$ phase.

Finally, the improvement of physical and biomedical properties by SPD is investigated in three papers. Lapovok et al. [11] studied the influence of ECAP on the electrical conductivity and strength of $\mathrm{Cu}$-clad $\mathrm{Al}$ conductors with different sheet thicknesses, which were subsequently annealed. Although the conductivity decreased after deformation, annealing led to conductivity values exceeding the predicted, theoretical ones. It could be shown that ECAP in combination with short annealing can be used to produce conductors with high conductivity and strength. Wurster et al. [12] investigated the influence of HPT such as deformation temperature and strain rate on the granular magnetoresistance of different materials consisting of ferromagnetic and diamagnetic elements and 
related it to the microstructure of SPD-processed materials. It is shown that the magnitude of the granular magnetoresistance can be tuned by changing the HPT process parameters. In [13], the effect of SMAT was compared for two binary functionally graded materials (Ti-Nb and Ti6Al4V-Mo) to study the effect of chemistry, roughness and SPD microstructure on mesenchymal stem cell adhesion and proliferation. The increased roughness introduced by SMAT improved the cellular adhesion, but did not influence their proliferation capability. It was further found that the SPD treatment has an effect on cell distribution during the first stages of proliferation due to the induced microstructural refinement and structural defects.

\section{Conclusion and Outlook}

The current Special Issue of Metals provides a comprehensive insight into current research in the field of SPD. The papers cover several research topics and we hope that this Special Issue will be a starting point for future scientific discussions. As Guest Editors of this Special Issue, we hope that the papers will catch the interest of many scientists and will be useful for their future work.

Acknowledgments: We would like to express our deep gratitude to all the authors for their contributions. We further thank the anonymous reviewers for their efforts to ensure high-quality publications were accepted. Sincere thanks are also due to the editors and editorial assistants of Metals for their help and support during the preparation of this Special Issue.

Conflicts of Interest: The authors declare no conflict of interest.

\section{References}

1. Klu, E.E.; Song, D.; Li, C.; Wang, G.; Zhou, Z.; Gao, B.; Sun, J.; Ma, A.; Jiang, J. Development of a High Strength Mg-9Li Alloy via Multi-Pass ECAP and Post-Rolling. Metals 2019, 9, 1008. [CrossRef]

2. Nugmanov, D.; Mazilkin, A.; Hahn, H.; Ivanisenko, Y. Structure and Tensile Strength of Pure Cu after High Pressure Torsion Extrusion. Metals 2019, 9, 1081. [CrossRef]

3. Stráská, J.; Minárik, P.; Šašek, S.; Veselý, J.; Bohlen, J.; Král, R.; Kubásek, J. Texture Hardening Observed in Mg-Zn-Nd Alloy Processed by Equal-Channel Angular Pressing (ECAP). Metals 2019, 10, 35. [CrossRef]

4. Dureau, C.; Novelli, M.; Arzaghi, M.; Massion, R.; Bocher, P.; Nadot, Y.; Grosdidier, T. On the Influence of Ultrasonic Surface Mechanical Attrition Treatment (SMAT) on the Fatigue Behavior of the 304L Austenitic Stainless Steel. Metals 2020, 10, 100. [CrossRef]

5. Wang, C.; Ma, A.; Sun, J.; Zhuo, X.; Huang, H.; Liu, H.; Yang, Z.; Jiang, J. Improving Strength and Ductility of a Mg-3.7Al-1.8Ca-0.4Mn Alloy with Refined and Dispersed Al2Ca Particles by Industrial-Scale ECAP Processing. Metals 2019, 9, 767. [CrossRef]

6. Ojdanic, A.; Horky, J.; Mingler, B.; Fanetti, M.; Gardonio, S.; Valant, M.; Sulkowski, B.; Schafler, E.; Orlov, D.; Zehetbauer, M.J. The Effects of Severe Plastic Deformation and/or Thermal Treatment on the Mechanical Properties of Biodegradable Mg-Alloys. Metals 2020, 10, 1064. [CrossRef]

7. Veverková, A.; Kozlík, J.; Bartha, K.; Chráska, T.; Corrêa, C.A.; Stráský, J. Mechanical Properties of Ti-15Mo Alloy Prepared by Cryogenic Milling and Spark Plasma Sintering. Metals 2019, 9, 1280. [CrossRef]

8. Kriegel, M.J.; Rudolph, M.; Kilmametov, A.; Straumal, B.B.; Ivanisenko, J.; Fabrichnaya, O.; Hahn, H.; Rafaja, D. Formation and Thermal Stability of $\omega$-Ti(Fe) in $\alpha$-Phase-Based Ti(Fe) Alloys. Metals 2020, 10, 402. [CrossRef]

9. Churakova, A.; Gunderov, D. Microstructural and Mechanical Stability of a Ti-50.8 at.\% Ni Shape Memory Alloy Achieved by Thermal Cycling with a Large Number of Cycles. Metals 2020, 10, 227. [CrossRef]

10. Bartha, K.; Stráský, J.; Veverková, A.; Barriobero-Vila, P.; Lukáč, F.; Doležal, P.; Sedlák, P.; Polyakova, V.; Semenova, I.; Janeček, M. Effect of the High-Pressure Torsion (HPT) and Subsequent Isothermal Annealing on the Phase Transformation in Biomedical Ti15Mo Alloy. Metals 2019, 9, 1194. [CrossRef]

11. Lapovok, R.; Dubrovsky, M.; Kosinova, A.; Raab, G. Effect of Severe Plastic Deformation on the Conductivity and Strength of Copper-Clad Aluminium Conductors. Metals 2019, 9, 960. [CrossRef] 
12. Wurster, S.; Weissitsch, L.; Stückler, M.; Knoll, P.; Krenn, H.; Pippan, R.; Bachmaier, A. Tuneable Magneto-Resistance by Severe Plastic Deformation. Metals 2019, 9, 1188. [CrossRef]

13. Weiss, L.; Nessler, Y.; Novelli, M.; Laheurte, P.; Grosdidier, T. On the Use of Functionally Graded Materials to Differentiate the Effects of Surface Severe Plastic Deformation, Roughness and Chemical Composition on Cell Proliferation. Metals 2019, 9, 1344. [CrossRef]

Publisher's Note: MDPI stays neutral with regard to jurisdictional claims in published maps and institutional affiliations.

(C) 2020 by the authors. Licensee MDPI, Basel, Switzerland. This article is an open access article distributed under the terms and conditions of the Creative Commons Attribution (CC BY) license (http://creativecommons.org/licenses/by/4.0/). 